\title{
Consumer effects on ecosystem functioning in rock pools: roles of species richness and composition
}

\author{
John N. Griffin ${ }^{1,2, *}$, Laure M.-L. J. Noël ${ }^{1,6}$, Tasman P. Crowe ${ }^{3}$, Michael T. Burrows ${ }^{4}$, \\ Stephen J. Hawkins ${ }^{1,5}$, Richard C. Thompson ${ }^{2}$, Stuart R. Jenkins ${ }^{1,5}$ \\ ${ }^{1}$ Marine Biological Association of the United Kingdom, The Laboratory, Citadel Hill, Plymouth PL1 2PB, UK \\ ${ }^{2}$ Marine Biology and Ecology Research Centre, School of Biological Sciences, University of Plymouth, \\ Plymouth PL4 8AA, UK \\ ${ }^{3}$ School of Biology and Environmental Science, University College Dublin, Belfield, Dublin 4, Ireland \\ ${ }^{4}$ The Scottish Association for Marine Science, Dunstaffnage Marine Laboratory, Oban, Argyll, PA37 1QA, UK \\ ${ }^{5}$ School of Ocean Sciences, University of Wales Bangor, Menai Bridge, Anglesey LL59 5AB, UK \\ ${ }^{6}$ CNRS, UPMC Université Paris 6, UMR 7144, Station Biologique de Roscoff, Place Georges Teissier, BP74, \\ 29682 Roscoff Cedex, France
}

\begin{abstract}
A key challenge in research linking biodiversity and ecosystem functioning is to incorporate the trophic interactions that characterise natural systems. There is a particular shortage of studies investigating consumer species richness and composition (identity) effects in the context of ecosystem development (or succession). We manipulated the richness and composition of an assemblage of molluscan grazers (Patella ulyssiponensis, Gibbula umbilicalis and Littorina littorea) added to rock pools denuded of existing biota. We created monocultures and all possible multispecies combinations in a substitutive design, and ran a field experiment for 13 mo. We used 2 separate nested analyses to isolate the roles of species richness, species composition nested within levels of species richness and the specific effect of the limpet $P$. ulyssiponensis, a putative key species. We found no evidence that the biomass or productivity of the developing macroalgal assemblage was affected by grazer richness or species composition nested within richness levels. Rather, the presence of $P$. ulyssiponensis, irrespective of the presence of other grazer species, acted to suppress mean values of these response variables. Biomass and productivity were not strongly related, showing that they provide unique information on ecosystem functioning in this system. Macroalgal species richness was also reduced by $P$. ulyssiponensis, and correlated positively with macroalgal biomass, indicating a link between these response variables. Macroalgal species composition was largely insensitive to either species richness or the presence of $P$. ulyssiponensis, but responded to particular combinations of species within levels of these factors. The key role of $P$. ulyssiponensis in determining ecosystem functioning is apparent from our results, but we note that consumer species richness may play an important role under more heterogeneous conditions.
\end{abstract}

KEY WORDS: Biodiversity · Ecosystem functioning $\cdot$ Grazing $\cdot$ Herbivory $\cdot$ Primary productivity · Succession $\cdot$ Species identity $\cdot$ Species richness

Resale or republication not permitted without written consent of the publisher

\section{INTRODUCTION}

Over the last 2 decades understanding the effects of biodiversity on ecosystem functioning has emerged as a fundamental research theme (reviewed by Loreau et al. 2001, Hooper et al. 2005, Balvanera et al. 2006,
Benedetti-Cecchi 2006, Cardinale et al. 2006, Stachowicz et al. 2007). In light of rapid and pervasive human alterations to biodiversity (Pimm et al. 1995, Worm et al. 2006, Byrnes et al. 2007), this issue has important implications for the management of ecosystem services (Kremen 2005). Early seminal work 
focused on the effect of plant richness on primary production in temperate grassland plots (e.g. Tilman 1996). Increasingly, however, both theoretical (Thébault \& Loreau 2003, Casula et al. 2006) and empirical work (reviewed by Duffy et al. 2007) has aimed to incorporate the trophic interactions that characterise natural systems, shifting emphasis towards the often complex effects of species diversity and composition in multitrophic food webs.

Species richness can enhance ecosystem processes through complementarity - a class of mechanisms that includes resource partitioning and facilitation (Loreau 2000). The action of such mechanisms requires the presence of trait diversity, typically represented by multiple species, and increases on average with species richness (Petchey \& Gaston 2002). Where interspecific resource partitioning occurs, for example, increasing species richness will allow a greater proportion of the resource spectrum to be used, potentially enhancing the associated ecosystem process above that of the single best-performing species (e.g. Råberg \& Kautsky 2007, Griffin et al. 2008).

While species richness may generally enhance ecosystem processes, there can be considerable, and even greater, variation in rates of ecosystem functioning within levels of species richness (Wojdak 2005). This variability can result from the inclusion or exclusion of particular species or combinations of species (Tilman 1996). Such composition (or identity) effects can predominate if one or several species are particularly well adapted to performing the process of interest, or where a combination of particular species results in an especially high level of resource partitioning or facilitation (e.g. Griffin et al. 2009a). Variation in ecosystem processes attributable to species composition may appear idiosyncratic and unpredictable (Naeem et al. 2002). However, in some cases, apparently idiosyncratic composition effects may be largely explained by the presence or absence of a single dominant species (Polley et al. 2007, O'Connor et al. 2008). Such species may exert a dominant influence on ecosystem functioning by virtue of their functional traits and high abundance (Grime 1998), such that they procure a large proportion of available resources and cannot be compensated for by other species (Schiel 2006). If one species is predicted a priori to be a key species, targeted comparisons of treatments with and without this species can test for its dominant effect on ecosystem functioning (O'Connor \& Crowe 2005, O'Connor et al. 2008).

Primary consumers (herbivores) play a critical role in many ecosystems, particularly in the marine environment, strongly affecting primary producer biomass, diversity and composition, with potentially large impacts on ecosystem functioning (e.g. McNaughton 1985,
Hughes 1994, Paine 2002, Worm et al. 2002). Theory predicts that consumer species richness will enhance the rate and breadth of resource uptake, reducing the biomass of primary producers (Holt \& Loreau 2001, Duffy 2002). Numerous studies have demonstrated effects of grazer richness and composition on the final and accumulated biomass of primary producers (upon termination of experiments) (e.g. Naeem \& Li 1997, Duffy et al. 2001, Gamfeldt et al. 2005). However, biomass accumulation measures the net balance of production and consumption and thus may be a poor measure of the rate of primary productivity when losses to consumers are high (Raffaelli \& Hawkins 1999). The potential mismatch between consumer effects on producer biomass and productivity may be further compounded by shifts in producer species composition (Duffy 2003) and/or stimulated mass-specific rates of primary production resulting from compensatory responses to grazing (Carpenter 1986) and/or reduced density dependence (Altieri et al. 2009). To our knowledge, however, no previous studies have quantified the effects of consumer species richness and composition on both primary producer biomass and productivity.

Herbivores are expected to have particularly marked effects on the recruitment and initial growth of primary producers, as the early life history stages of primary producers lack the mechanisms that protect them from predation as adults (Santelices 1990, Carson \& Root 1999). Disturbances are typically patchy (Dethier 1984), allowing mobile herbivores to migrate into a recently disturbed area from surrounding unaffected habitat (Hartnoll \& Hawkins 1985, Burrows \& Hawkins 1998). During the early stages of community development, following the loss of a pre-existing community or the creation of new habitat, herbivores may thus have strong effects on community composition (Hawkins 1981, Lubchenco 1983, Lotze et al. 2001, Belliveau \& Paul 2002), diversity (Lubchenco 1978), biomass (e.g. Hixon \& Brostoff 1996) and productivity (Masterson et al. 2008).

We present the findings of a field experiment designed to determine the independent effects of and distinguish between - consumer species richness, species composition and the presence of a putative key species on the development and functioning of macroalgal assemblages in rock pools. We used relatively homogeneous artificial intertidal pools located on a breakwater in the UK, naturally dominated by diverse erect assemblages of macroalgae (Griffin 2008). Pioneering (Jones 1946) and recent (Paine 2002, Jenkins et al. 2005, Moore et al. 2007) field research has shown that consumers as a group can play an important role in controlling macroalgal communities on rocky shores (see Jenkins et al. 2008 for review). 
O'Connor \& Crowe (2005) tested the effect of consumer identity and richness on mature macroalgal assemblages in intertidal pools in Ireland, but the study presented here represents the first test on the recruitment phase in this system. Patellid limpets typically reach larger body sizes and maintain larger standing stocks than do other molluscan grazers on exposed rocky shores in northwestern Europe (Jenkins et al. 2001). Coupled with their powerful rasping foraging technique, these traits produce a strong impact on the standing stock of macroalgal assemblages (Moore et al. 2007). Based on previous research (Hawkins 1981, Hawkins \& Hartnoll 1983), and consistent with O'Connor \& Crowe (2005), we put forward the orangefooted limpet Patella ulyssiponensis as a key species in this system.

We manipulated the richness and composition of 3 locally abundant grazers (Gibbula umbilicalis, Littorina littorea and Patella ulyssiponensis, as in O'Connor \& Crowe 2005) and quantified treatment-specific effects on the structure and functioning of developing rock pool communities. Specifically, we quantified effects on the structure (species composition and diversity) and functioning (biomass and productivity) of developing macroalgal assemblages. We first posited that community structure and functioning will be determined by richness, not the composition of grazer species (Hypothesis 1). We also tested the hypothesis that the presence of $P$. ulyssiponensis affects community structure and functioning regardless of the presence or absence of other grazer species (Hypothesis 2). Subsets of treatments were compared to address these distinct hypotheses.

\section{MATERIALS AND METHODS}

Study site. We conducted this experiment using relatively homogeneous intertidal rock pools situated on the seaward side of a large coastal defence structure, the Plymouth breakwater (completed in 1841, approximately $1.5 \mathrm{~km}$ long and $0.1 \mathrm{~km}$ wide), on the English Channel coast, southern UK. Two pools, separated by approximately $1.5 \mathrm{~m}$, are located on the upper surfaces of each of numerous large concrete blocks $(2.5 \mathrm{~m}$ high, and $2.4 \times 4.8 \mathrm{~m}$ on their upper surface). Compared with natural rock pools, the dimensions of the pools vary minimally (mean $\pm \mathrm{SD}$ : depth $=0.31 \pm 0.04 \mathrm{~m}$; total rock surface area $=0.806 \pm 0.088 \mathrm{~m}^{2} ;$ volume $=54.48 \pm$ 7.63 1). They have vertical sides, making area and volume calculations simple. The pools are subject to natural colonisation and hosted communities that resemble those of natural rock pools in the region, with macroalgal assemblages being dominant. The orientation and positioning of the blocks subject the pools to similar wave exposure (moderate to high) and tidal height (ca. $3 \mathrm{~m}$ above chart datum). Additionally, the physical homogeneity of the pools themselves (size, rugosity and substrate material) created an opportunity to isolate the role of consumers in a relatively controlled setting whilst maintaining exposure of assemblages to the natural marine environment.

Experimental design and establishment. The total area of substrate ([perimeter $\times$ depth] + pool surface area) and volume (pool surface area $\times$ depth) of each pool were calculated from digital images (Image $\mathrm{J}^{\mathrm{TM}}$ ). With entire pools forming the replicate units, we manipulated both the richness and composition of 3 consumer species added to the pools: the orangefooted limpet Patella ulyssiponensis, the topshell Gibbula umbilicalis and the periwinkle Littorina littorea (as in O'Connor \& Crowe 2005); hereafter, these species are referred to by their generic names only in full or as an initial (i.e. P, G or L, respectively). We selected these species because they are the most abundant primary consumers in midshore rock pools at local sites (J. Griffin unpubl. data) and, thus, most likely to have strong influences on ecosystem processes (Grime 1998). We incorporated a range of sizes within each species (maximum shell length): Littorina, 14 to $18 \mathrm{~mm}$; Gibbula, 12 to $14 \mathrm{~mm}$; Patella, 25 to $40 \mathrm{~mm}$.

We included all species in monocultures (G, L, P), all 3 possible 2-species combinations (GL, GP, LP) and a treatment containing all 3 species (GLP). Additionally, grazer-free caged (CC) and uncaged controls (UC) allowed us to test for the effect of cages on response variables. Subsets of treatments were compared to test our 2 hypotheses.

We employed a substitutive design such that initial total consumer density $\left(\sim 14 \mathrm{~g}\right.$ shell-free dry mass $\left.\mathrm{m}^{-2}\right)$ was equalised across treatments varying in richness, requiring a reduction in the density of component species with increasing richness. The substitutive design makes the assumption that after local extinction of species, those remaining compensate for their loss by increasing in numbers or biomass, i.e. show density compensation (e.g. Griffin et al. 2008). Since 'extinct' species are replaced by individuals of those remaining, this design tests whether functional compensation would be possible given biomass compensation and reveals the net effect of intraspecific and interspecific interactions (Jolliffe 2000, Griffen 2006).

Initial biomass of grazers was always equally divided among species present (i.e. $14 \mathrm{~g} \mathrm{~m}^{-2}$ per number of species). Previous work on nearby rocky shores (Noël 2007, Noël et al. 2009) showed that this biomass density was well within the natural range of variability of total biomass of these 3 species (6.2 to $25.7 \mathrm{~g}$ shell-fee dry biomass $\mathrm{m}^{-2}$ ) and also close to their mean $( \pm 1 \mathrm{SD})$ summed biomass $(13.31 \pm 4.91 \mathrm{~g}$ shell-fee dry biomass 
$\mathrm{m}^{-2}$ ). Before the addition of grazers, pools were emptied of water and all organisms (including existing grazers) were manually removed. Using a large propane burner, we subsequently cleared all remaining macrobiota from the pools, ensuring that all remnants of the pre-existing communities (including highly resistant coralline forms) were visibly removed. Cages ( $8 \mathrm{~mm}$ stainless steel welded wire mesh, chosen to also allow passage of light and propagules) were then constructed over pools to maintain experimental treatments by preventing grazer dispersal and immigration of large-bodied grazers.

Grazers were collected from local shores, carefully transplanted to a Perspex substrate and maintained in flowing seawater for no more than $3 \mathrm{~d}$ before transplantation to the study pools. Two weeks after the initial establishment of treatments, we checked the abundance of grazers and added individuals to maintain equal densities to compensate for transplantinduced mortality (primarily of Patella). Secondary additions were largely successful. Visual estimates of density at the midpoint in the experiment $(6 \mathrm{mo})$ showed that all grazers had suffered considerable, but variable, rates of mortality. This could have been caused by resource limitation early in the experiment. Patella was able to maintain a higher biomass than the other 2 species. In line with a standard substitutive experiment, we aimed to re-equilibrate interspecific densities. We thus added appropriate numbers of Gibbula and Littorina to reach a biomass equal to the mean biomass of Patella (in treatments with an equal number of species) after 6 mo. To avoid promoting possible negative density-dependent effects, we did not keep 'topping-up' treatments throughout the remainder of the experiment ( 7 to $12 \mathrm{mo}$ ). Instead, we allowed grazer densities to change through the second half of the experiment and interpreted results in light of these final densities. Specifically, final grazer biomass varied among species (Fig. 1); thus, speciesspecific effects were a combination of functional traits and biomass effects (see 'Discussion'). Importantly, species-specific biomasses in multispecies treatments conformed to a substitutive design with unequal monoculture densities (single species biomass/number of species, Griffin et al. 2009b), and each species was proportionally represented in multispecies treatments according to their monoculture densities. Mean total grazer biomass in multispecies treatments thus closely approximated that expected from species-specific final biomasses in single-species treatments (dotted lines in Fig. 1; 1-sample $t$-tests against expected: GL, $\mathrm{p}=0.36$; GP, $p=0.40 ; \mathrm{LP}, \mathrm{p}=0.77$; GLP, $\mathrm{p}=0.226$ ). With the caveat that species-specific effects included speciesspecific biomass effects, our hypotheses could be tested with confidence.

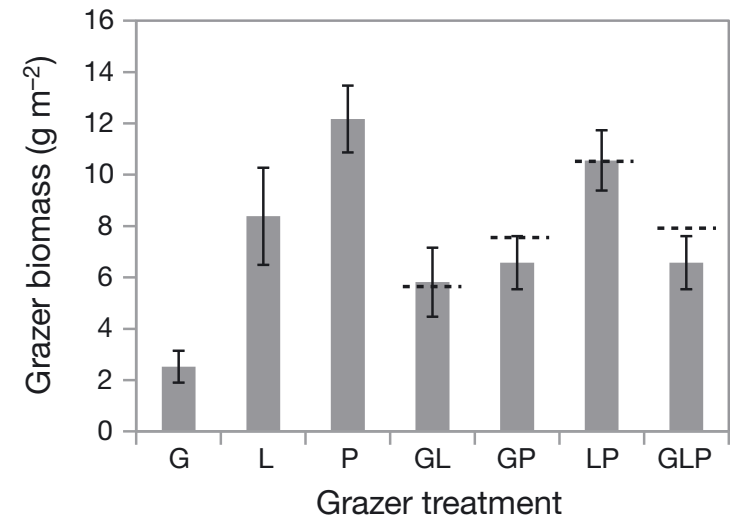

Fig. 1. Mean $( \pm \mathrm{SE})$ final biomass (shell-free) of manipulated grazers according to treatment. Single-species treatments are G: Gibbula, L: Littorina, P: Patella. Two-species treatments are GL: Gibbula + Littorina; GP: Gibbula + Patella; LP: Littorina + Patella. Three-species treatment is GLP: Gibbula, Littorina and Patella. Starting biomass was $\sim 14 \mathrm{~g} \mathrm{~m}^{-2}$ in each treatment; the biomass of grazers thus fell in all treatments. Dashed lines indicate the biomass expected in multiple species treatments based on the final mean of component monocultures

Each treatment had 4 replicates, giving a total of 36 pools studied. Treatments were randomly assigned to pools, resulting in interspersed replicates. The manipulations were fully established in July 2006 and ran for a total of 13 mo until late August 2007. The cages were thoroughly cleaned every 3 to 4 mo throughout the experiment to prevent the excessive build-up of ephemeral algae, which could shade the underlying pools.

Measurement and calculation of response variables. All response variables were measured upon termination of the experiment. We estimated instantaneous gross primary productivity by measuring rates of oxygen flux between biota and the discrete body of water (the pool) in both light and artificially darkened conditions (see Nielsen 2001, Martins et al. 2007, Noël et al. 2010 for detailed descriptions of this technique applied to rock pools). We measured the concentration of oxygen in each rock pool (HQ20 Hach Portable LDO ${ }^{\mathrm{TM}}$ ) before and after an hour-long dark period (community respiration) and finally after a period of re-exposure to natural light (including both photosynthesis and community respiration). Gross primary productivity was calculated by simply compensating net oxygen flux under light conditions with oxygen consumption under darkened conditions (Nielsen 2001). Measurements were made in each pool on 3 replicate days under consistently bright, sunny conditions (23 to 25 August 2007), before averaging the values for each pool. We corrected rates of oxygen exchange for diffusion at the water-air interface by applying a diffusion constant $\left(K=0.32 \mathrm{~g} \mathrm{~m}^{-2} \mathrm{~h}^{-1}\right)$ calculated for shallow $(<1 \mathrm{~m})$ shel- 
tered water with very limited wave action (see Kinsey 1985 for correction methodology). We standardised measures of gross primary productivity (GPP) to both the total surface area of the pool (area-specific GPP; e.g. Martins et al. 2007) and the mass of macroalgae (biomass-specific GPP; e.g. Littler \& Littler 1980). Our approach, which focuses on benthic algal productivity, has been verified by Martins et al. (2007) who showed that the rate of primary productivity in rock pools typical of UK rocky shores is almost totally (>98\%) driven by macroalgae, with $<2 \%$ attributable to phytoplankton.

Following measurement of oxygen flux rates, the abundances of all macroalgal taxa within each pool was ascertained. Firstly, we estimated the percentage cover of encrusting coralline algae and bare rock within 4 replicate $400 \mathrm{~cm}^{2}$ quadrats (Dethier 1984). Secondly, we collected all erect macroalgae from all pools. We then sorted these in the laboratory to the lowest taxonomic level possible (mostly to species), dried all these taxa in the oven at $60^{\circ} \mathrm{C}$ for $3 \mathrm{~d}$ and reweighed them (De Wreede 1985). Approximately $80 \%$ of the biomass of Corallina officinalis consists of its heavy calcite skeleton; thus, raw dry mass measures of macroalgal assemblages in rock pools can largely reflect the abundance of this one species (Griffin 2008). We thus converted dry biomass measures of Corallina officinalis to calcium carbonate-free measures using a conversion factor of 0.2 estimated from laboratory dissolution of calcite in weak acid (Carpenter 1986, Griffin 2008).

As an additional measure of ecosystem-level grazer treatment effects we calculated the total mass of macroalgae by summing the masses of component species and normalised to per $\mathrm{m}^{2}$ of of pool substrate. Richness (number), evenness (Pielou's $J^{\prime}$ ) and diversity (Shannon's $H^{\prime}$ ) (see e.g. Magurran 2004) of macroalgae were also calculated.

The relative tolerance of macroalgal taxa to consumption is probably related to their functional morphology (Steneck \& Dethier 1994). Effects of consumption are thus likely to be most evident when macroalgal taxa are grouped according to morphology and/or functional traits. Macroalgal taxa were therefore further divided into morpho-functional groups (i.e. crustose coralline, foliose, canopy, sheet-like and turfforming) according to known functional attributes of the species (categories adapted from Littler \& Littler 1980, Arenas et al. 2006).

Analysis. All measures of functioning and diversity were considered in separate univariate analyses. Treatment effects on the composition of macroalgal (morpho-functional groups and taxa) assemblages were assessed through multivariate analyses. However, crustose coralline algae and bare rock were both measured as proportions of total substrate coverage $(\%)$, thus were not comparable to biomass measures of morpho-functional groups. We therefore analysed treatment effects on these variables through separate univariate analyses.

To test both of our hypotheses we used ANOVA for univariate response variables and a permuted multivariate ANOVA (PERMANOVA) (Anderson 2001) for multivariate responses. To test Hypothesis 1 we used a 2 -factor nested model with 3 levels of species composition nested within both single $(\mathrm{P}, \mathrm{L}, \mathrm{G})$ and 2 species (GL, GP, LP) levels of species richness (Model 1), a model similar to that used in several previous biodiversity-ecosystem functioning experiments (Jonsson \& Malmqvist 2000, O'Connor \& Crowe 2005, Wojdak 2005). As a complementary test of Hypothesis 1, and to test for an effect of consumer species richness at the 3-species level, we calculated the expected value of each univariate response variable at the 3-species level as the average of single-species effects on this response. We then compared the observed values with expected mean values using 2-tailed 1-sample $t$-tests (Barton \& Schmitz 2009). To test Hypothesis 2, we conducted planned comparisons to directly compare treatments with Patella (P, GP, LP, GLP) to those without Patella (CC, L, G, GL). This was also a 2-way nested analysis with species composition nested within treatments with or without Patella (Model 2; see O'Connor \& Crowe 2005 and O'Connor et al. 2008 for a comparable approach).

Univariate analyses were validated through Cochran's test for heterogeneous variances, multivariate analysis through the PERMDISP2 (Anderson 2006) procedure, which tests for heterogeneity in multivariate dispersion between treatments. Under Model 2 (Hypothesis 2) area-specific GPP was log transformed to achieve homogeneous variances.

Where PERMANOVA with pairwise comparisons identified significant between-group differences in composition (of macroalgal taxa, morpho-functional groups or animal taxa), the 'Similarity Percentages' (SIMPER) procedure was used to identify those taxa or groups underlying the difference (Clarke \& Warwick 2001). Multivariate analyses were performed on BrayCurtis dissimilarity measures and permuted 999 times.

To check whether the cages used to contain the manipulated grazers significantly affected response variables, we conducted both univariate and multivariate comparisons detailed above between caged (CC) and uncaged (UC) control treatments. Univariate analyses were performed in GMAV (Institute of Marine Ecology, University of Sydney), multivariate analyses in PRIMER (Clarke \& Warwick 2001).

Finally, to explore relationships between univariate response variables across the entire data set, we per- 
formed correlation analyses. Specifically, we tested the correlations between macroalgal diversity (richness, $H^{\prime}$ and $J^{\prime}$ ) and measures of ecosystem functioning (area-specific productivity, mass-specific productivity and biomass). Additionally, given the effects of grazing by Patella on both area-specific productivity and biomass, we explored the link between these 2 responses through correlation.

\section{RESULTS}

A single replicate from each of the treatments, L, G and $\mathrm{CC}$, was excluded from the experiment owing to damage to cages after winter storms. Analyses were performed by using the average of the 3 remaining replicates in each of the relevant treatments to balance our design and reduce the degrees of freedom appropriately (Underwood 1997). Comparisons between caged and uncaged grazer-free controls indicated that cages did not have a significant effect on any of the univariate or multivariate responses $(p>0.1$ in all cases).

Neither grazer richness nor composition within levels of species richness affected macroalgal biomass (Fig. 2) or either of the measures of GPP (Fig. 3, Table 1, Model 1). All 3 grazers in combination suppressed macroalgal biomass $44 \%$ below the expected level (Fig. 2) (based on monoculture performance), although this was not statistically significant (1-sample $t$-test, $\mathrm{p}=0.08$ ). The presence of Patella, on the other hand, significantly reduced both macroalgal biomass and the rate of area-specific productivity (Fig. 2, Table 1, Model 2).

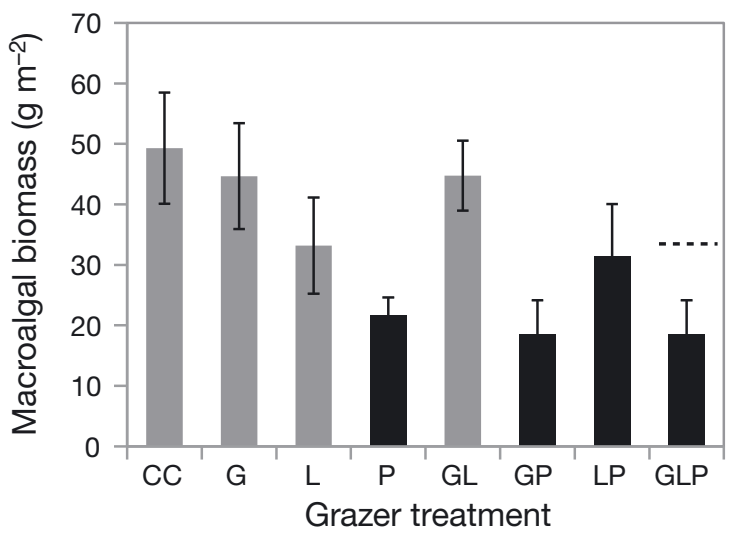

Fig. 2. Treatment means $( \pm \mathrm{SE})$ of accumulated macroalgal biomass. CC: grazer-free (caged) control; all other treatment codes as in Fig. 1. The dashed line indicates the expected level of macroalgal biomass in the 3-species treatment (GLP) based on the mean of component monocultures. Black bars: treatments with Patella; grey bars: treatments without Patella. See Table 1 for ANOVA
Multivariate analyses showed the relative abundances and composition of macroalgal taxa were not significantly affected by species richness, composition within levels of richness (Table 2, Model 1) or the presence of Patella (Table 2, Model 2). At the level of morpho-functional group, however, effects of species composition within richness levels (Table 2, Model 1, $\mathrm{GL} \neq \mathrm{GP}$ ), in addition to composition within levels of Patella (Table 2, Model 2, CC $\neq$ GL), were detected. Specifically, within the 2-species level (Model 1) GL resulted in a greater abundance of turf-forming algae (32.3\% of difference, SIMPER) but less canopy algae ( $24.9 \%$ of difference) than did GP. GL also had more turf-forming algae (33.7\% of difference), although it had less sheet-like algae than CC (16.6\% of difference) (Patella absent, Model 2).

Neither species richness nor composition within species richness levels affected the cover of bare rock or crustose coralline algae (Table 3, Model 1). The presence of Patella did, however, result in a significantly greater coverage of bare rock (Table 3, Model 2), while Patella had no effect on the cover of crustose coralline algae.
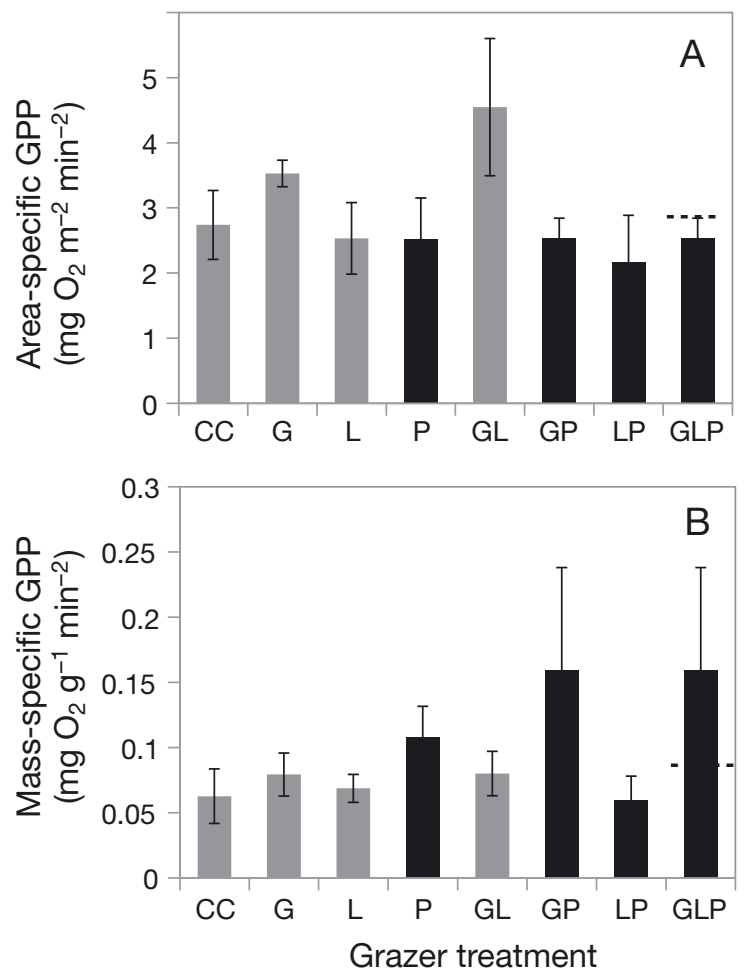

Fig. 3. Treatment means $( \pm \mathrm{SE})$ of $(\mathrm{A})$ area-specific gross primary productivity (GPP) and (B) mass-specific GPP. See Table 1 for ANOVA and post-hoc tests. Treatment codes are as in Figs. 1 \& 2. The dashed line indicates the expected level of macroalgal biomass in the 3-species treatment (GLP) based on the mean of component monocultures. Black bars: treatments with Patella; grey bars: treatments without Patella. See Table 1 for ANOVA 
Macroalgal species richness was not affected by grazer richness or composition within richness levels; however, macroalgal diversity $\left(H^{\prime}\right)$ was significantly lower at the 2-species level compared with the 1species level (Fig. 4, Table 4, Model 1). This reduction in diversity can be attributed to a lower level of macroalgal species evenness in 2 species mixtures (Table 4, Model 1). The effect of grazer richness did not extend to the highest level of grazer richness; the observed levels of macroalgal richness ( $p=0.16)$, diversity $(p=0.27)$ and evenness $(p=0.58)$ did not differ from expected (1-sample $t$-tests; Fig. 4). The pres-
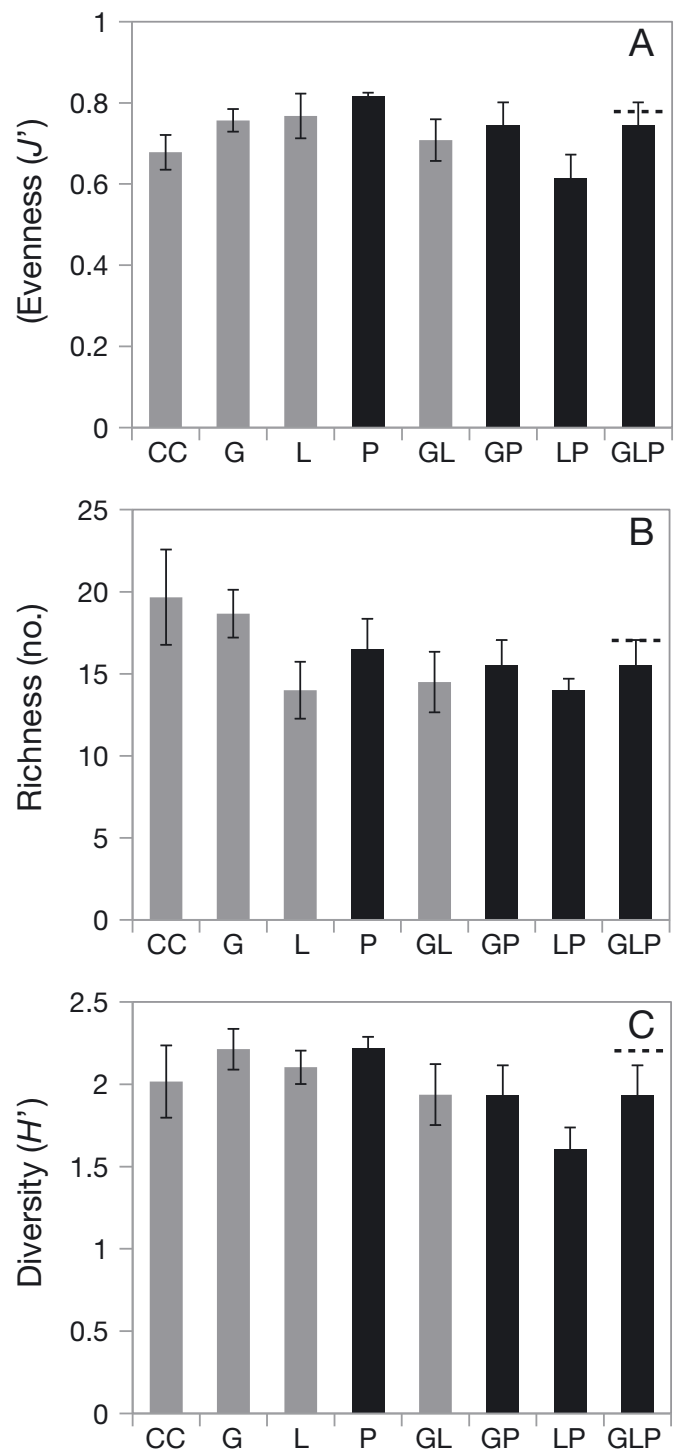

Fig. 4. Treatment means $( \pm \mathrm{SE})$ of macroalgal species (A) evenness $\left(J^{\prime}\right)$, (B) richness (number [no.]) and (C) diversity $\left(H^{\prime}\right)$. Treatment codes are as in Figs. $1 \& 2$. The dashed line indicates the expected level of macroalgal biomass in the 3 -species treatment (GLP) based on the mean of component monocultures. Black bars: treatments with Patella; grey bars: treatments without Patella. See Table 4 for ANOVA ence of Patella significantly reduced the richness of macroalgae but had no effect on macroalgal diversity $\left(H^{\prime}\right)$ or evenness $\left(J^{\prime}\right)$ (Fig. 4, Table 4, Model 2).

Across all caged study pools, macroalgal species richness was positively correlated with macroalgal biomass (Table 5), while macroalgal species evenness displayed the opposite (negative) relationship with macroalgal biomass (Table 5). No measure of macroalgal diversity was related to either measure of productivity. Notably, the 2 measures of ecosystem functioning that were affected by Patella (biomass and area-specific productivity) were not correlated $(\mathrm{r}=0.20, \mathrm{p}=0.30, \mathrm{n}=29)$.

\section{DISCUSSION}

Our results show that the effects of consumers on the structure and functioning of developing macroalgal assemblages were largely determined by the inclusion of the limpet Patella ulyssiponensis. Specifically, Patella reduced the richness and biomass of macroalgae, increased the cover of bare substrate and suppressed the rate of gross primary productivity.

Our findings must be interpreted in light of changes in grazer biomass that occurred during the experiment (given the equalising of species' biomass densities at the start and midpoint of the experiment, see 'Materials and methods'). Total grazer biomass fell during the experiment in all treatments, indicating that grazer mortality exceeded growth. The reduction in grazer biomass varied among species, which can be most clearly seen at the single species level. Gibbula suffered a far higher level of biomass reduction compared with the other 2 species (Fig. 1). This is unlikely to be a result of the stress of transplantation; in a previous laboratory experiment (Griffin et al. 2009b) we found no transplant-induced mortality in this species. Although previous work shows that Gibbula can reach the high biomass densities established in single-species treatments at the start of the experiment (Noël et al. 2009), the physical (e.g. wave exposure) and biological (e.g. algal habitat provision) conditions at the study site evidently did not suit Gibbula as much as it did the other 2 species. Food limitation of Gibbula may also help to explain this species' relatively high mortality rate, given that Gibbula has the smallest mean body size of all the grazers used here and relative metabolic demand is greater in smaller-bodied organisms (West et al. 1997).

Consistent with the idea that species impacts on ecosystem functioning will be related to their biomass (Grime 1998), in this experiment, as in natural pools (Manley 2008), species-specific grazing effects cannot be separated from biomass effects. This should not be considered as a confounding effect; rather, biomass acts 
Table 1. Analysis of treatment effects on accumulated macroalgal biomass and productivity response (GPP) variables. Model 1 shows results of nested ANOVA to test Hypothesis 1. Model 2 shows results of nested ANOVA used to test Hypothesis 2. p-values in bold text denote significant effects (at alpha level = 0.05). NB: residual df reduced from 18 to 16 (Model 1) and from 24 to 21 (Model 2) owing to missing replicates

\begin{tabular}{|c|c|c|c|c|c|c|c|c|c|c|}
\hline \multirow[t]{2}{*}{ Source of variation } & \multirow[b]{2}{*}{$\mathrm{df}$} & \multicolumn{3}{|c|}{ Macroalgal biomass } & \multicolumn{3}{|c|}{ Area-specific GPP } & \multicolumn{3}{|c|}{ Mass-specific GPP } \\
\hline & & MS & $F$ & $\mathrm{p}$ & MS & $F$ & $\mathrm{p}$ & MS & $F$ & $\mathrm{p}$ \\
\hline \multicolumn{11}{|l|}{ Model 1} \\
\hline Richness & 1 & 188.66 & 0.54 & 0.51 & 0.02 & $<0.01$ & 0.95 & $<0.01$ & 2.19 & 0.21 \\
\hline Composition (Richness) & 4 & 352.53 & 2.02 & 0.14 & 4.68 & 3.19 & 0.06 & $<0.01$ & 1.03 & 0.42 \\
\hline Residual & 16 & 174.49 & & & 1.69 & & & $<0.01$ & & \\
\hline \multicolumn{11}{|l|}{ Model 2} \\
\hline \pm Patella & 1 & 1795.6 & 6.28 & 0.05 & 0.59 & 6.68 & 0.04 & $<0.01$ & 0.79 & 0.41 \\
\hline Composition $( \pm$ Patella $)$ & 6 & 286.06 & 1.64 & $0.19 a$ & 0.09 & 0.96 & 0.47 & $<0.01$ & 1.1 & 0.4 \\
\hline Residual & 21 & 174.98 & & & 0.09 & & & $<0.01$ & & \\
\hline
\end{tabular}

in combination with species' functional traits to determine their effects (Grime 1998, Garnier et al. 2004, Vile et al. 2006). We suggest that future experiments should not necessarily aim to equalise biomass or numbers across all treatments as in a traditional substitutive de-

Table 2. Results of PERMANOVA testing for treatment effects on the composition of macroalgal species and morpho-functional group. Model 1 shows results of multivariate nested ANOVA to test Hypothesis 1; Model 2 shows results of multivariate nested ANOVA used to test Hypothesis 2. p-values in bold text denote significant effects (at alpha level $=0.05$ ). This analysis excludes crustose coralline algae

\begin{tabular}{|c|c|c|c|c|c|c|c|}
\hline \multirow[t]{2}{*}{ Source of variation } & \multirow[b]{2}{*}{ df } & \multicolumn{3}{|c|}{ Macroalgal species } & \multicolumn{3}{|c|}{$\begin{array}{c}\text { Macroalgal } \\
\text { morpho-functional } \\
\text { groups }\end{array}$} \\
\hline & & MS & $F$ & $\mathrm{p}$ & MS & $F$ & $\mathrm{p}$ \\
\hline \multicolumn{8}{|l|}{ Model 1} \\
\hline Richness & 1 & 1333.9 & 1.1268 & 0.37 & 442.72 & 0.71 & 0.76 \\
\hline Composition (richness) & 4 & 4752.8 & 1.3777 & 0.09 & 623.79 & 1.95 & 0.04 \\
\hline Residual & 16 & 13799 & & & 319.94 & & \\
\hline \multicolumn{8}{|l|}{ Model 2} \\
\hline \pm Patella & 1 & 1929 & 1.78 & 0.13 & 962.92 & 1.62 & 0.2 \\
\hline Composition $( \pm$ Patella) & 6 & 1087 & 1.24 & 0.14 & 596.79 & 1.68 & 0.02 \\
\hline Residual & 21 & 878.07 & & & 355.94 & & \\
\hline
\end{tabular}

Table 3. Analysis of treatment effects on the percentage covers of bare rock and crustose coralline algae. $p$-values in bold text denote significant effects (at alpha level $=0.05$ ). NB: residual $\mathrm{df}$ reduced from 18 to 16 (Model 1) and from 24 to 21 (Model 2) owing to missing replicates

\begin{tabular}{|c|c|c|c|c|c|c|c|}
\hline \multirow[t]{2}{*}{ Source of variation } & \multirow[b]{2}{*}{$\mathrm{df}$} & \multicolumn{3}{|c|}{$\%$ bare rock } & \multicolumn{3}{|c|}{$\begin{array}{c}\% \text { crustose coralline } \\
\text { algae }\end{array}$} \\
\hline & & MS & $F$ & $\mathrm{p}$ & MS & $F$ & $\mathrm{p}$ \\
\hline \multicolumn{8}{|l|}{ Model 1} \\
\hline Richness & 1 & 1180.67 & 0.55 & 0.50 & 86.89 & 0.49 & 0.52 \\
\hline Identity (richness) & 4 & 2156.82 & 2.84 & 0.06 & 177.48 & 0.59 & 0.68 \\
\hline Residual & 16 & 758.18 & & & 300.68 & & \\
\hline \multicolumn{8}{|l|}{ Model 2} \\
\hline \pm Patella & 1 & 8911.13 & 7.76 & 0.03 & 12.29 & 0.06 & 0.81 \\
\hline Composition $( \pm$ Patella $)$ & 6 & 1148.24 & 1.62 & 0.19 & 201.34 & 0.82 & 0.57 \\
\hline Residual & 21 & 707.92 & & & 246.43 & & \\
\hline
\end{tabular}

sign (as we did), but ensure that interspecific differences in standing stock are represented from the beginning of the experiment (see Griffin et al. 2009b for an example of this approach). This may be no simple task, however, given that species' biomasses and effects on ecosystem functioning can be highly context-dependent, and this is especially true in heterogeneous environments such as rocky shores (Griffin et al. 2009b). This agues for site replication in future studies, as well as an explicit consideration of the effect of environmental variables on species' abundances and contributions to ecosystem functioning.

To our knowledge this experiment is the first to examine how consumer composition and diversity affect both producer standing stock and the gross rate of primary productivity. Our results show that the dominant negative effect of Patella on macroalgal biomass was also apparent in reduced rates of areaspecific GPP, demonstrating an impact by this species on both stock and flux elements of ecosystem functioning (Chapin et al. 2000). These effects also suggest that the reduction in areaspecific GPP may have been mediated by Patella's effect on algal biomass, although this is not supported by the weak correlation between macroalgal biomass and area-specific GPP (Table 5). Subtle and possibly interacting effects of grazers on the relative abundances of macroalgal taxa, macroalgal diversity and density-dependent competition or facilitation could all help to explain the lack of correspondence between macroalgal biomass and GPP overall. It is beyond the scope of the present study 
Table 4. Nested ANOVA on aspects of macroalgal species diversity. p-values in bold text denote significant effects (at alpha level $=0.05$ ). NB: residual df reduced from 18 to 16 (Model 1) and from 24 to 21 (Model 2) owing to missing replicates

\begin{tabular}{|c|c|c|c|c|c|c|c|c|c|c|}
\hline \multirow[t]{2}{*}{ Source of variation } & \multirow[b]{2}{*}{$\mathrm{df}$} & \multicolumn{3}{|c|}{ Richness (no.) } & \multicolumn{3}{|c|}{ Diversity $\left(H^{\prime}\right)$} & \multicolumn{3}{|c|}{ Evenness $\left(J^{\prime}\right)$} \\
\hline & & MS & $F$ & $\mathrm{p}$ & MS & $F$ & $\mathrm{p}$ & MS & $F$ & $\mathrm{p}$ \\
\hline \multicolumn{11}{|l|}{ Model 1} \\
\hline Richness & 1 & 18.37 & 2.56 & 0.19 & 0.71 & 8.31 & 0.04 & 0.062 & 7.47 & 0.05 \\
\hline Composition (richness) & 4 & 7.18 & 0.71 & 0.59 & 0.09 & 1.34 & 0.30 & $<0.01$ & 1.39 & 0.28 \\
\hline Residual & 16 & 10.13 & & & 0.06 & & & $<0.01$ & & \\
\hline \multicolumn{11}{|l|}{ Model 2} \\
\hline \pm Patella & 1 & 68.06 & 7.79 & 0.03 & 0.15 & 0.99 & 0.36 & 0.15 & 0.99 & 0.30 \\
\hline Composition $( \pm$ Patella $)$ & 6 & 8.73 & 0.75 & 0.62 & 0.15 & 1.88 & 0.13 & 0.15 & 1.88 & 0.13 \\
\hline Residual & 21 & 11.69 & & & 0.08 & & & 0.08 & & \\
\hline
\end{tabular}

to elucidate these possible effects, but we note that the noisy and possibly nonlinear relationship between these 2 related response variables (biomass and productivity) underlines that biomass accumulation should be used only with caution as a proxy of productivity in studies of consumer impacts (Masterson et al. 2008), and that these 2 response variables provide unique information on the effects of consumer richness and composition on ecosystem functioning.

Patella grazing did not cause any consistent changes in the composition of macroalgae, at the level of taxa or even morpho-functional group (Table 2), indicating that macroalgal taxa were similarly affected by Patella regardless of their morpho-functional traits. Patella did not reduce the species diversity $\left(H^{\prime}\right)$ or evenness $\left(J^{\prime}\right)$ of macroalgae, providing a further indication that the presence of Patella affected macroalgal taxa indiscriminately. Therefore, the observed reduction of macroalgal species richness in the presence of Patella (Fig. 4b) cannot be attributed to the vulnerability of particular species (or a morpho-functional group) to Patella grazing. The positive correlation between macroalgal biomass and species richness (Table 5) shows that a greater number of species are represented with an increasing abundance (biomass) of macroalgae, which may be purely a result of increasing 'sampling' of individuals, analogous to the welldocumented species-accumulation curves produced when sampling for species richness estimation (e.g. Gotelli \& Colwell 2001). Additional possible explana-

Table 5. Pearson's correlations between aspects of macroalgal diversity and measures of ecosystem functioning recorded across all pools studied (excluding uncaged controls). Significant correlations are shown in bold text. $\mathrm{n}=29$

\begin{tabular}{|lccccccc|}
\hline & \multicolumn{2}{c}{ Biomass } & \multicolumn{3}{c|}{ Area-specific } & \multicolumn{2}{c|}{ Mass-specific } \\
& $\mathrm{r}$ & $\mathrm{p}$ & $\mathrm{c}$ productivity & \multicolumn{2}{c}{ productivity } \\
& & & $\mathrm{r}$ & $\mathrm{p}$ & $\mathrm{r}$ & $\mathrm{p}$ \\
\hline Species richness $(\mathrm{no})$ & $\mathbf{0 . 4 5 5}$ & $\mathbf{0 . 0 1 3}$ & 0.312 & 0.100 & -0.297 & 0.118 \\
Species diversity $\left(H^{\prime}\right)$ & -0.099 & 0.609 & 0.159 & 0.410 & -0.029 & 0.882 \\
Species evenness $\left(J^{\prime}\right)$ & $\mathbf{- 0 . 4 1 8}$ & $\mathbf{0 . 0 2 4}$ & -0.004 & 0.985 & 0.187 & 0.33 \\
\hline
\end{tabular}

tions for this correlation include an increase in associational defenses (e.g. Pfister \& Hay 1988, Noël 2007) with macroalgal biomass and/or a positive effect of macroalgal richness on biomass accumulation through resource complementarity (Bruno et al. 2006). The fact that species evenness decreases with biomass (Table 5) indicates that the species that accumulate with increasing biomass remain rare, suggesting that they are probably epiphytic species gaining an associational defense on better-defended high biomass species (Noël 2007).

In contrast to the strong effects of grazing by Patella, grazer species richness did not affect the biomass or functioning of macroalgae. This is at odds with patterns emerging from a large number of empirical studies (reviewed by Hooper et al. 2005, Cardinale et al. 2006, Stachowicz et al. 2007) that show rates of resource consumption to be generally enhanced by increasing species richness. While our results imply that species richness does not affect resource consumption in this system, greater consideration of this apparent departure from theory is required. Firstly, our gradient of species richness was very limited (1 to 3 species), including only the most abundant grazers found on local rocky shores. This may have limited the strength of a species complementarity effect by offering limited functional diversity. Grazers from other phyla, such as the crustacean amphipods and isopods, may, for example, offer a greater potential for resource complementarity due to larger differences in feeding mode (Parker et al. 1993, Råberg \& Kautsky 2007). Secondly, the relatively homogeneous conditions afforded by these artificial pools (e.g. substrate type and rugosity, tidal height and exposure) may have prevented interspecific complementarity from being realised in terms of resource use partitioning (Cardinale et al. 2004, Griffin et al. 2009b). Finally, while species richness effects on ecosystem functioning were not de- 
tected here, we note that our results do suggest that grazer richness is important in this system, despite the dominant effects of grazing by Patella. Macroalgal biomass was reduced to a greater degree than expected in the 3-species mixture (Fig. 2). Although this was not statistically significant $(p=0.08)$, greater replication may have allowed detection of this possible diversity effect. Given the marginal significance of the richness effect, as well as the limited replication in our study, we feel it is premature to conclude that richness does not increase the strength of consumer control of macroalgae in this system.

A further suggestion that grazer richness affected macroalgae was apparent in macroalgal diversity $\left(H^{\prime}\right)$ and evenness $\left(J^{\prime}\right)$, which were both lower when 2 species of grazers were present compared with when a single grazer was present (Table 4, Fig. 4). At the 3 -species level there was no effect of grazer richness on macroalgal diversity or evenness (Fig. 4), which calls for a cautious interpretation of the effect of 1 versus 2 species on macroalgal diversity and evenness. Further empirical work is required to elucidate the effects of consumer diversity on resource diversity in this system and more generally.

Strong effects of species identity, as documented here, have been a common feature of biodiversityecosystem functioning research in studies ranging through primary producers (e.g. Bruno et al. 2005), consumers (e.g. Duffy et al. 2001) and predators (e.g. Straub \& Snyder 2006). The obvious implication is that to understand and predict ecosystem functioning, we need to consider the identity of species lost or gained. Understanding effects of species based on their functional traits may allow functionally important species to be identified based on the biomass-weighted value of their functional traits (Garnier et al. 2004, Vile et al. 2006). However, over larger temporal and spatial scales species complementarity, and thus diversity, may become important (Cardinale et al. 2004, 2007). In relation to our study, experiments including the full range of habitat types and environmental contexts over which the focal species coexist, and over multigenerational time periods, would be required before one could conclude that the ecosystem functions measured here could be maintained by the single dominant species, Patella ulyssiponensis.

Acknowledgements. This work forms part of the PhD studentship of J.N.G. funded by the National Environmental Research Council (NERC) and tied to standard grant NE/B504649/1 (to S.R.J., R.C.T., S.J.H, M.T.B. and T.P.C.). A. Bates, M. Melton, T. Noble, V. Mendez, M. Lilley and P. Masterson provided invaluable assistance with fieldwork. This work would not have been possible without access to Plymouth Breakwater generously granted by the Queen's Harbour Master.

\section{LITERATURE CITED}

Altieri AH, Trussell GC, Ewanchuk PJ, Bernatchez G, Bracken MES (2009) Consumers control diversity and functioning of a natural marine ecosystem. PLoS ONE 4: e5291

Anderson MJ (2001) A new method for non-parametric multivariate analysis of variance. Austral Ecol 26:32-46

Anderson MJ (2006) Distance-based tests for homogeneity of multivariate dispersions. Biometrics 62:245-253

Arenas F, Sanchez I, Hawkins SJ, Jenkins SR (2006) The invasibility of marine algal assemblages: role of functional diversity and identity. Ecology 87:2851-2861

> Balvanera P, Pfisterer AB, Buchmann N, He JS, Nakashizuka T, Raffaelli D, Schmid B (2006) Quantifying the evidence for biodiversity effects on ecosystem functioning and services. Ecol Lett 9:1146-1156

Barton BT, Schmitz OJ (2009) Experimental warming transforms multiple predator effects in a grassland food web. Ecol Lett 12:1317-1325

Belliveau SA, Paul VJ (2002) Effects of herbivory and nutrients on the early colonization of crustose coralline and fleshy algae. Mar Ecol Prog Ser 232:105-114

Benedetti-Cecchi L (2006) Understanding the consequences of changing biodiversity on rocky shores: How much have we learned from past experiments? J Exp Mar Biol Ecol 338:193-204

Bruno JF, Boyer KE, Duffy JE, Lee SC, Kertesz JS (2005) Effects of macroalgal species identity and richness on primary production in benthic marine communities. Ecol Lett 8:1165-1174

> Bruno JF, Lee SC, Kertesz JS, Carpenter RC, Long ZT, Duffy JE (2006) Partitioning the effects of algal species identity and richness on benthic marine primary production. Oikos 115:170-178

> Burrows MT, Hawkins SJ (1998) Modelling patch dynamics on rocky shores using deterministic cellular automata. Mar Ecol Prog Ser 167:1-13

> Byrnes JE, Reynolds PL, Stachowitz JJ (2007) Invasions and extinctions reshape coastal food webs. PLoS ONE 2:e295

Cardinale BJ, Wright JP, Cadotte MV, Corroll IT, Hector A, Srivastava DS, Loreau M, Weis JJ (2007) Impacts of plant diversity on biomass production increase through time because of species complementarity. Proc Natl Acad Sci USA 104:18123-18128

Cardinale BJ, Ives AR, Inchausti P (2004) Effects of species diversity on the primary productivity of ecosystems: extending our spatial and temporal scales of inference. Oikos 104:437-450

Cardinale BJ, Srivastava DS, Duffy JE, Wright JP, Downing AL, Sankaran M, Jouseau C (2006) Effects of biodiversity on the functioning of trophic groups and ecosystems. Nature 443:989-992

> Carpenter RC (1986) Partitioning herbivory and its effects on coral-reef algal communities. Ecol Monogr 56:345-363

> Carson WP, Root RB (1999) Top-down effects of insect herbivores during early succession: influence on biomass and plant dominance. Oecologia 121:260-272

Casula P, Wilby A, Thomas MB (2006) Understanding biodiversity effects on prey in multi-enemy systems. Ecol Lett 9:995-1004

> Chapin FS III, Zaveleta ES, Eviner VT, Naylor RL and others (2000) Consequences of changing biotic diversity. Nature 405:234-242

Clarke KR, Warwick RM (2001) Change in marine communities: an approach to statistical analysis and interpretation. PRIMER-E, Plymouth 
Dethier MN (1984) Disturbance and recovery in rockpools: maintainence of mosaic patterns. Ecol Monogr 54:99-118

De Wreede RE (1985) Destructive (harvest) sampling. In: Littler MM, Littler DS (eds) Handbook of phycological methods. Ecological field methods: macroalgae. Cambridge University Press, Cambridge, p 147-160

$>$ Duffy JE (2002) Biodiversity and ecosystem function: the consumer connection. Oikos 99:201-219

$>$ Duffy JE (2003) Biodiversity loss, trophic skew and ecosystem functioning. Ecol Lett 6:680-687

Duffy JE, Macdonald KS, Rhode JM, Parker JD (2001) Grazer diversity, functional redundancy, and productivity in seagrass beds: an experimental test. Ecology 82:2417-2434

Duffy JE, Cardinale BJ, France KE, McIntyre PB, Thébault E, Loreau M (2007) The functional role of biodiversity in ecosystems: incorporating trophic complexity. Ecol Lett 10:522-538

Gamfeldt L, Hillebrand H, Jonsson PR (2005) Species richness changes across two trophic levels simultaneously affect prey and consumer biomass. Ecol Lett 8:696-703

> Garnier E, Cortez J, Bille G, Navas ML and others (2004) Plant functional markers capture ecosystem properties during secondary succession. Ecology 85:2630-2637

Gotelli NJ, Colwell RK (2001) Quantifying biodiversity: procedures and pitfalls in the measurement and comparison of species richness. Ecol Lett 4:379-391

Griffen BD (2006) Detecting emergent effects of multiple predator species. Oecologia 146:608-614

Griffin JN (2008) Biodiversity and ecosystem functioning: tests using rockpools as experimental mesocosms. Marine Biology and Ecology Research Centre/Marine Biological Assocation of the UK, University of Plymouth

Griffin JN, de la Haye KL, Hawkins SJ, Thompson RC, Jenkins SJ (2008) Predator diversity and ecosystem functioning: Density modifies the effect of resource partitioning. Ecology 89:298-305

> Griffin JN, Mendez V, Johnson AF, Jenkins SR, Foggo A (2009a) Functional diversity predicts overyielding effect of species combination on primary productivity. Oikos 118: $37-44$

> Griffin JN, Jenkins SR, Gamfeldt L, Jones D, Hawkins SJ, Thompson RC (2009b) Spatial heterogeneity increases the importance of species richness for an ecosystem process. Oikos 118:1335-1342

> Grime JP (1998) Benefits of plant diversity to ecosystems: immediate, filter and founder effects. J Ecol 86:902-910

Hartnoll RG, Hawkins SJ (1985) Patchiness and fluctuations on moderately exposed rocky shores. Ophelia 24:53-63

Hawkins SJ (1981) The influence of season and barnacles on the algal colonization of Patella vulgata exclusion areas. J Mar Biol Assoc UK 61:1-15

Hawkins SJ, Hartnoll RG (1983) Grazing of intertidal algae by marine invertebrates. Oceanogr Mar Biol Annu Rev 21: 195-285

> Hixon MA, Brostoff WN (1996) Succession and herbivory: effects of differential fish grazing on Hawaiian coral-reef algae. Ecol Monogr 66:67-90

Holt RD, Loreau M (2001) Biodiversity and ecosystem functioning: the role of trophic interactions and the importance of system openness. In: Kinzig AP, Pacala SW, Tilman D (eds) The functional consequences of biodiversity. Princeton University Press, Princeton, NJ, p 246-262

> Hooper DU, Chapin FS, Ewel JJ, Hector A and others (2005) Effects of biodiversity on ecosystem functioning: a consensus of current knowledge. Ecol Monogr 75:3-35

> Hughes TP (1994) Catastrophes, phase-shifts, and large-scale degradation of a Caribbean coral-reef. Science 265:1547-1551
Jenkins SR, Arenas F, Arrontes J, Bussell JA and others (2001) European-scale analysis of seasonal variability in limpet grazing activity and microalgal abundance. Mar Ecol Prog Ser 211:193-203

> Jenkins SR, Coleman RA, Della Santina P, Hawkins SJ, Burrows MT, Hartnoll RG (2005) Regional scale differences in the determinism of grazing effects in the rocky intertidal. Mar Ecol Prog Ser 287:77-86

Jenkins SR, Moore P, Burrows MT, Garbary DJ and others (2008) Comparative ecology of North Atlantic shores: Do differences in players matter for process? Ecology 89: S3-S23

Jollife PA (2001) The replacement series. J Ecol 88:371-385

Jones NS (1946) Browsing of Patella. Nature 158:557-558

Jonsson M, Malmqvist B (2000) Ecosystem process rate increases with animal species richness: evidence from leaf-eating, aquatic insects. Oikos 89:519-523

Kinsey DW (1985) Open-flow systems. In: Littler MM, Littler DS (eds) Handbook of phycological methods. Ecological field methods: macroalgae. Cambridge University Press, Cambridge, p 427-460

Kremen C (2005) Managing ecosystem services: What do we need to know about their ecology? Ecol Lett 8:468-479

Littler MM, Littler DS (1980) The evolution of thallus form and survival strategies in benthic marine macroalgae: field and laboratory tests of a functional form model. Am Nat 116:25-44

Loreau M (2000) Biodiversity and ecosystem functioning: recent theoretical advances. Oikos 91:3-17

Loreau M, Naeem S, Inchausti P, Bengtsson J and others (2001) Biodiversity and ecosystem functioning: current knowledge and future challenges. Science 294:804-808

Lotze HK, Worm B, Sommer U (2001) Strong bottom-up and top-down control of early life stages of macroalgae. Limnol Oceanogr 46:749-757

> Lubchenco J (1978) Plant species diversity in a marine intertidal community: importance of herbivore food preference and algal competitive abilities. Am Nat 112:23-39

> Lubchenco J (1983) Littorina and Fucus: effects of herbivores, substratum heterogeneity, and plant escapes during succession. Ecology 64:1116-1123

Magurran AE (2004) Measuring biological diversity. Blackwell, Oxford

Manley R (2008) The functional diversity of consumers on a rocky shore. MSc thesis, University of Plymouth

Martins GM, Hawkins SJ, Thompson RC, Jenkins SR (2007) Community structure and functioning in intertidal rock pools: effects of pool size and shore height at different successional stages. Mar Ecol Prog Ser 329:43-55

Masterson P, Arenas FA, Thompson RC, Jenkins SR (2008) Interaction of top down and bottom up factors in intertidal rockpools: effects on early successional macroalgal community composition, abundance and productivity. J Exp Mar Biol Ecol 363:12-20

McNaughton SJ (1985) Ecology of a grazing ecosystem - the Serengeti. Ecol Monogr 55:259-294

> Moore P, Thompson RC, Hawkins SJ (2007) Effects of grazer identity on the probability of escapes by a canopy-forming macroalga. J Exp Mar Biol Ecol 344:170-180

Naeem S, Li SB (1997) Biodiversity enhances ecosystem reliability. Nature 390:507-509

Naeem S, Loreau M, Inchausti P (2002) Biodiversity and ecosystem functioning: the emergence of a synthetic ecological framework. In: Loreau M, Naeem S, Inchausti $\mathrm{P}$ (eds) Biodiversity and ecosystem functioning: synthesis and perspectives. Oxford University Press, Oxford, p 3-11 Nielsen KJ (2001) Bottom-up and top-down forces in tide 
pools: test of a food chain model in an intertidal community. Ecol Monogr 71:187-217

Noël LMLJ (2007) Species interactions during succession in rockpools: role of herbivores and physical factors. $\mathrm{PhD}$ thesis, University of Plymouth

Noël LMLJ, Hawkins SJ, Jenkins SR, Thompson RC (2009) Grazing dynamics in intertidal rockpools: connectivity of microhabitats. J Exp Mar Biol Ecol 370:9-17

Noël LMLJ, Griffin JN, Thompson RC, Hawkins SJ, Burrows MT, Crowe TP, Jenkins SR (2010) Assessment of a field incubation method estimating primary productivity in rockpool communities. Estuar Coast Shelf Sci 88:153-159

O'Connor NE, Crowe TP (2005) Biodiversity loss and ecosystem functioning: distinguishing between number and identity of species. Ecology 86:1783-1796

O'Connor NE, Grabowski JH, Ladwig LM, Bruno JF (2008) Simulated predator extinctions: predator identity affects survival and recruitment of oysters. Ecology 89:428-438

Paine RT (2002) Trophic control of production in a rocky intertidal community. Science 296:736-739

Parker T, Johnson C, Chapman ARO (1993) Gammarid amphipods and littorinid snails have significant but different effects on algal succession in littoral fringe tidepools. Ophelia 38:69-88

Petchey OL, Gaston KJ (2002) Functional diversity (FD), species richness and composition. Ecol Lett 5:402-411

Pfister CA, Hay ME (1988) Associational plant refuges: convergent patterns in marine and terrestrial communities result from differing mechanisms. Oecologia 77:118-129

Pimm SL, Russell GJ, Gittleman JL, Brooks TM (1995) The future of biodiversity. Science 269:347-350

Polley HW, Wilsey BJ, Derner JD (2007) Dominant species constrain effects of species diversity on temporal variability in biomass production of tallgrass prairie. Oikos 116: 2044-2052

Råberg S, Kautsky L (2007) Consumers affect prey biomass and diversity through resource partitioning. Ecology 88: 2468-2473

Raffaelli DG, Hawkins SJ (1999) Intertidal ecology. Chapman

Editorial responsibility: Lisandro Benedetti-Cecchi, Pisa, Italy
\& Hall, London

Santelices B (1990) Patterns of reproduction, dispersal and recruitment in seaweeds. Oceanogr Mar Biol Annu Rev $28: 177-276$

- Schiel DR (2006) Rivets or bolts? When single species count in the function of temperate rocky reef communities. J Exp Mar Biol Ecol 338:233-252

Stachowicz JJ, Bruno JF, Duffy JE (2007) Understanding the effects of marine biodiversity on communities and ecosystems. Annu Rev Ecol Evol Syst 38:739-766

> Steneck RS, Dethier MN (1994) A functional group approach to the structure of algal dominated communities. Oikos 69:476-498

> Straub CS, Snyder WE (2006) Species identity dominates the relationship between predator biodiversity and herbivore suppression. Ecology 87:277-282

Thébault E, Loreau M (2003) Food-web constraints on biodiversity-ecosystem functioning relationships. Proc Natl Acad Sci USA 100:14949-14954

> Tilman D (1996) Biodiversity: population versus ecosystem stability. Ecology 77:350-363

Underwood AJ (1997) Experiments in ecology: their logical design and interpretation using analysis of variance. Cambridge University Press, Cambridge

> Vile D, Shipley B, Garnier E (2006) Ecosystem productivity can be predicted from potential relative growth rate and species abundance. Ecol Lett 9:1061-1067

West GB, Brown JH, Enquist BJ (1997) A general model for the origin of allometric scaling laws in biology. Science 276:122-126

Wojdak JM (2005) Top down, bottom up, and consumer species richness effects on ecosystems: context dependency and relative effects strangth. Ecol Monogr 79:489-504

> Worm B, Lotze HK, Hillebrand H, Sommer U (2002) Consumer versus resource control of species diversity and ecosystem functioning. Nature 417:848-851

Worm B, Barbier EB, Beaumont N, Duffy JE and others (2006) Impacts of biodiversity loss on ocean ecosystem services. Science 314:787-790

Submitted: December 5, 2008; Accepted: September 23, 2010 Proofs received from author(s): December 4, 2010 